\title{
Sustainability and power in health promotion: community-based participatory research in a reproductive health policy case study in New Mexico
}

\author{
Rosilda Mendes 1 , Veronica Plaza ${ }^{2}$ and Nina Wallerstein ${ }^{3}$
}

\begin{abstract}
Health promotion programs are commonly viewed as value-free initiatives which seek to improve health, often through behavior change. An opposing view has begun to emerge that health promotion efforts, especially ones seeking to impact health policy and social determinants of health, are vulnerable to political contexts and may depend on who is in power at the time. This communitybased participatory research study attempts to understand these interactions by applying a conceptual model focused on the power context, diverse stakeholder roles within this context, and the relationship of political levers and other change strategies to the sustainability of health promotion interventions aimed at health policy change. We present a case study of a health promotion coalition, New Mexico for Responsible Sex Education (NMRSE), as an example of power dynamics and change processes. Formed in 2005 in response to federal policies mandating abstinence-only education, NMRSE includes community activists, health promotion staff from the New Mexico Department of Health, and policy-maker allies. Applying an adapted Mayer's 'power analysis' instrument, we conducted semi-structured stakeholder interviews and triangulated political-context analyses from the perspective of the stakeholders.

We identified multiple understandings of sustainability and health promotion policy change, including: the importance of diverse stakeholders working together in coalition and social networks; their distinct positions of power within their political contexts; the role of science versus advocacy in change processes; the particular challenges for public sector health promotion professionals; and other facilitators versus barriers to action. One problem that emerged consisted of the challenges for state employees to engage in health promotion advocacy due to limitations imposed on their activities by state and federal policies. This investigation's results include a refined conceptual model, a power-analysis instrument, and new understandings of the intersection of power and stakeholder strategies in the sustainability of health promotion and health in all policies. (Global Health Promotion, 2016; 23(1): 61-74)
\end{abstract}

Keywords: health promotion, reproductive health, policy, empowerment, community-based participatory research, prevention, schools, education settings, adolescents and youth

\section{Introduction}

The challenge of the sustainability of health promotion initiatives has often been discussed by health promotion professionals, but little research has been conducted on the impacts of power, policy actors, and political parties on sustainability per se. With health policy a core health promotion strategy within the Ottawa Charter, questions about

1. Universidade Federal de São Paulo - Campus Baixada Santista, Brazil.

2. University of New Mexico, Albuquerque, New Mexico, USA.

3. University of New Mexico - Public Health Program, Albuquerque, New Mexico, USA.

Correspondence to: Nina Wallerstein, University of New Mexico - Public Health Program, MSC 09_5060, Albuquerque, New Mexico 87131, USA. Email: nwallerstein@salud.unm.edu

(This manuscript was submitted on 11 November 2013. Following blind peer review, it was accepted for publication on 22 July 2014)

Global Health Promotion 1757-9759; Vol 23(1): 61-74; 550255 Copyright () The Author(s) 2014, Reprints and permissions: http://www.sagepub.co.uk/journalsPermissions.nav DOI: 10.1177/1757975914550255 http://ghp.sagepub.com 
sustainability may arise most often during times of political transitions in governments. At these times, health promotion efforts, especially those with controversial health policy agendas, may be threatened in their support, their access to resources, or their ability to maintain meaningful changes that lead to improved population health. The survival of health promotion initiatives may often depend on the role of stakeholders outside of government: their positions of power; their abilities to formulate political agendas; and, possibly most importantly, their ability to construct social networks, coalitions, or organized constituencies to sustain their efforts.

In its simplest form, sustainability can be defined as longevity and the ability of health promotion initiatives to be institutionalized within existing program, government, or community infrastructures. While the Ottawa Charter of Health Promotion does not identify sustainability as a specific goal, the confluence of the five Ottawa strategies implies ongoing conditions are needed through supportive environments and healthy public policy to enable healthier lives and communities. Within the literature, definitions generally divide into technical and political aspects of the term. A literature review, from 2000-present, using the keywords sustainability and health promotion, and conducted in three languages, English, Portuguese, and Spanish (within PubMED, LILAS, and SCIELO), found a range of technical functions to support sustainability, such as planning skills, assessments of impact, resources, organizational capacity and practices, institutional standards, and professional motivation (1-8). The literature on political dimensions focused on governance, the accountability of governmental bodies to the public; and the creation of intergovernmental systems that involve government workers, community members, and elected officials in the intersection of healthy policy development, and which aid or interfere with continuity of health promotion programs and policies (9-16). Within political dimensions, the role of intersectoral networks and coalitions at the community level is highlighted, with their capacity to promote sustainability through collaborative actions targeting health policy change well-articulated in the WHO Adelaide statement on 'health in all policies' (17). While North American literatures often use the terms 'coalitions' and 'partnerships', the WHO health promotion literature, reinforced by literature from Latin America, tends to use 'intersectoral networks' or 'social networks'. (We will use these terms interchangeably in this article.)

With sustainability benefiting from the actions of inter-sectoral networks with their shared models, analyses, and visions, multiple authors recommend analyzing the longitudinal dimension of projects and policies, including adequacy of resources, as part of the evaluation of impact, especially during moments of political transition and new governments. Characteristics of partnerships that facilitate project maintenance $(18-22)$ were identified as having a social determinants' perspective, as well as fostering active social participation, community capacity, and leadership empowerment (23-28).

The theme of 'sustainable development', especially within the environmental literature, has been subject to much debate. Most recently, Rio+20, the United Nations Conference on Sustainable Development, called for bringing together the fields of health promotion and social determinants in order to achieve the Millenium Development Goals. Unequal structural distribution of power within current systems of production and consumption were named as creating social and health inequities and limiting development. This analysis reinforces the importance of governance, participation, and especially social and political movements against corporate and policy-generated inequities as critical for genuine sustainable development $(29,30)$.

Despite the growth of a multi-faceted literature on sustainability, what has been missing is a deeper understanding of the interaction of dimensions of power, political participation and the capacity of health promotion initiatives to be sustained through policy and community capacity-building. Seen through the lens of a dynamic interplay of community members, their social networks, and governmental actors, Boaventura de Sousa Santos expresses this quality of dynamism of social actors well, calling social change: 'not the automatic result of some essential contradiction, but as created and creative results of created and created contradictions' (31).

This paper tackles the research question of how inter-sectoral actors and networks create and negotiate power levers, and broker relationships between government actors and communities, in order to promote and maintain desired health promotion policy transformations that support the 
sustainability of the health initiative. More specifically, our interest is in the extent to which health coalitions and networks with a diverse composition of social actors and staying power can influence health policy change through ongoing collective actions, even during transitions or contentions between political parties and ideologies.

Using a case study of an existing comprehensive reproductive health coalition in New Mexico, we applied an innovative power-analysis methodology to explore the power relationships between a health coalition of community members, organizations, and staff participants from the New Mexico Department of Health; abstinence-only opponents to the coalition; and policy-makers, including state and federal politicians. Our goal was to use this analysis to assess the coalition's capacity and impact on the sustainability of reproductive health promotion policy in New Mexico. We first present our community-based participatory methodology with a health promotion team in New Mexico, our co-development of specific research questions and a conceptual model to direct the study, our choice of a power-analysis instrument, and our interview sample. We then present our data analyses and results of the case study, with implications for future health promotion practice and research integrating power analyses and strategies in order to achieve sustainable health promotion initiatives.

\section{Research methods}

Using a community-based participatory research (CBPR) approach, the research team consisted of a faculty member from the Universities of New Mexico and São Paulo (the latter a visiting scholar at UNM in 2006), along with a health promotion specialist from the New Mexico Department of Health (NMDOH), who was also a founding member of the reproductive health coalition. To start our study, we invited the health promotion team (herein HP team) from the largest region of the $\mathrm{NMDOH}$ to participate with us in our inquiry in order to provide a complementary practice-based perspective. Over a six month process, in monthly meetings, the health promotion team defined and identified barriers and facilitators to sustainability in their own health promotion practice. After each meeting, the research team prepared written syntheses of the discussions, which they re-presented back to the HP team for continued reflection and collaborative knowledge creation. To assist in our dialogues with the HP team, we created an integration of the research literature of facilitators and barriers to sustainability with their practice-based perspectives to showcase the technical versus the political/ethical dimensions of the issue (Figure 1). We jointly systematized these concepts into a conceptual model of the 'dynamics of power and sustainability' (Figure 2), including power contexts and roles of social actors, technical and political change processes and strategies, systems outcomes, and health goals.

\section{Case study research design and implementation}

Using the model as a backdrop, the research team then selected the case, reviewed the national and state policy contexts of the health issue, and identified Mayer's 'power analysis' instrument to interview key stakeholders (32). This power-analysis instrument enabled us to focus on specific dimensions in the model, i.e. policy contexts, power relationships among stakeholders or social actors, stakeholder roles in health promotion advocacy and decisionmaking, and the impact of stakeholders' positions of power on the creation and long-term durability of beneficial health promotion policy.

Criteria for the choice of case study included a health promotion coalition with multiple social actors, an empowering agenda for its members, the potential for sustainability even with political change, and having health policy goals. We chose New Mexico for Responsible Sex Education (NMRSE), a coalition of more than 20 local organizations and advocates, health promotion staff from the Department of Health, religious leaders, policymakers, parents, and youth. It was formed in 2005 to provide advocacy, information, and support for ageappropriate, medically accurate, and comprehensive sexuality health education.

A key informant interview design was chosen to explore stakeholder perspectives on sexuality education health promotion, the coalition's capacity to influence policy, and the role of political power and context in shaping coalition strategies. We adapted and shortened the power-analysis tool (32) to 22 questions to focus on core components of our inquiry: personal characteristics and involvement of coalition members and opponents; interactions 


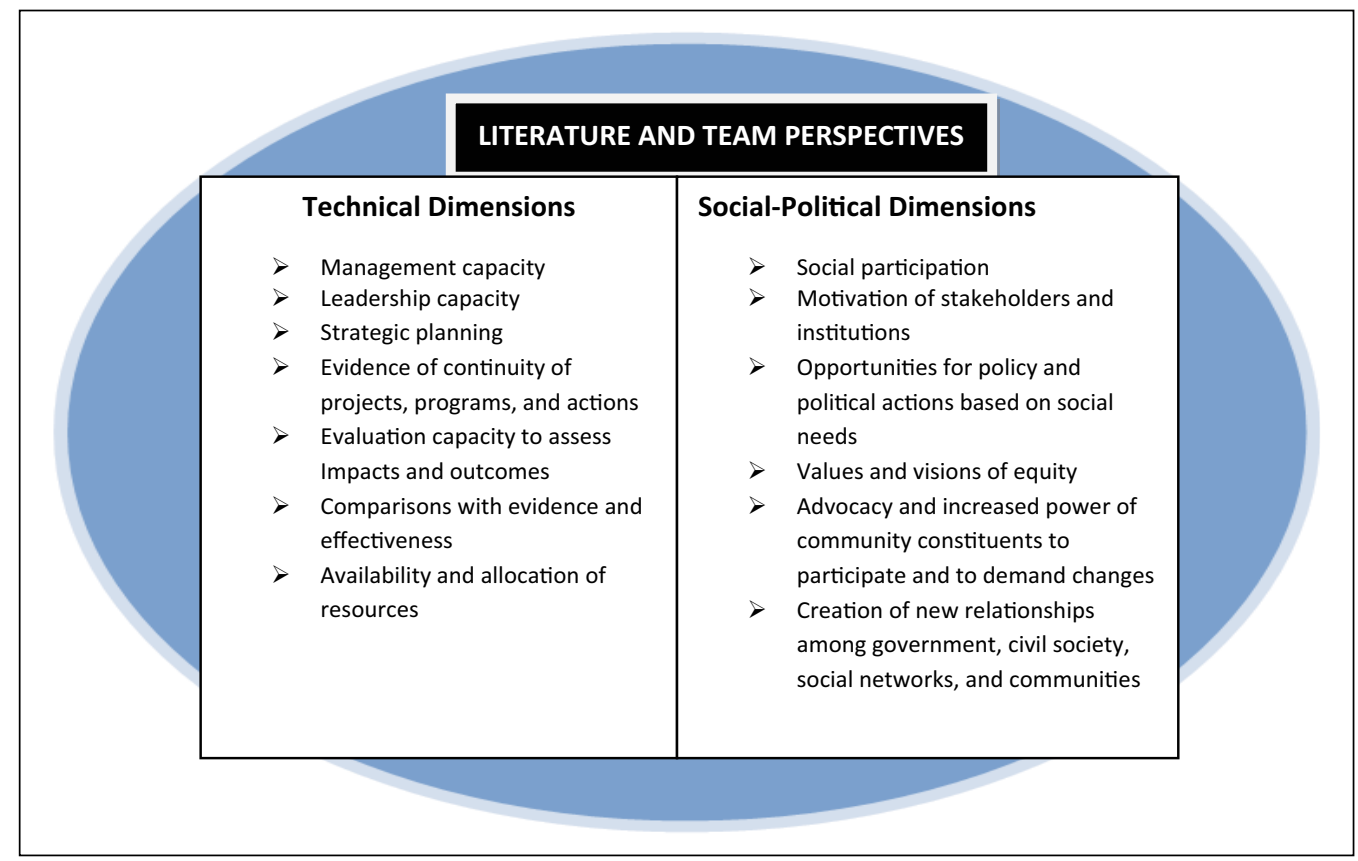

Figure 1. Syntheses of sustainability: theory and practice.

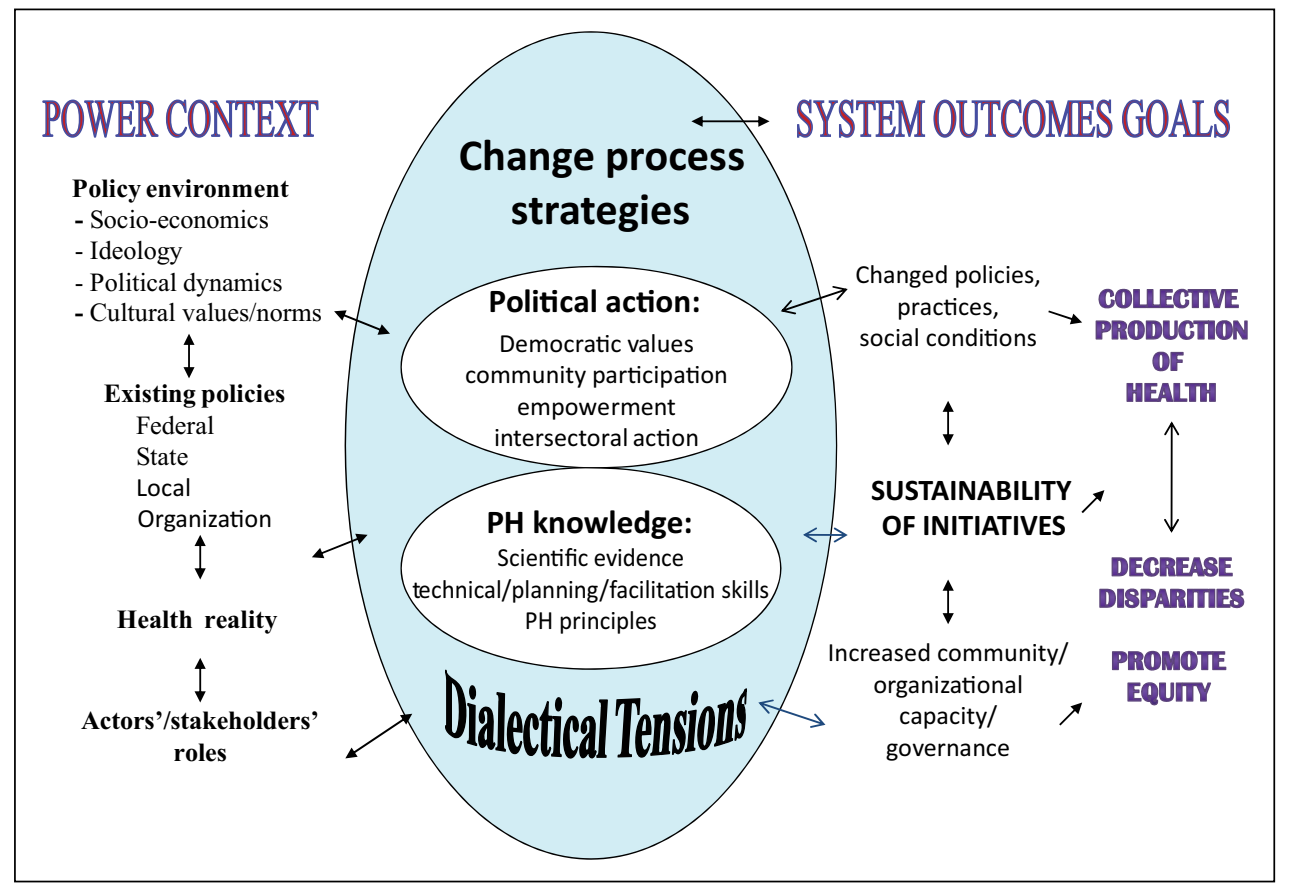

Figure 2. Dynamics of power and sustainability.

PH: Public Health. 
among coalition participants as a social network; potential and strategies of stakeholders to influence policy change; stakeholders' organizational and political contexts; and options and challenges for the future. We interviewed 15 key informants who had high participation in supporting or opposing comprehensive sexual health policies: five coalition members (community members and health promotion staff), one policy official who worked with the coalition, six higher-level NMDOH managers, and three members of groups who opposed comprehensive sex education. Four invitees declined to be interviewed (two members of abstinence-only groups and two NMDOH leaders). Each interview was audio-taped and transcribed, with identifiers removed from the interviews before data analysis. Participants gave their consent to be interviewed and signed consent forms, designed and approved under the standard NMDOH protocol, as an assessment of the NMDOH's work with the coalition.

Two of the investigator team coded the transcripts (comparing coding on the first set of interviews and re-coding to reach consensus), first by questions from the power-analysis tool and from constructs presented in Figure 1, and secondly by being open to emergent themes from the data using grounded theory (33). Themes and subthemes were then organized into matrices based on the overall categories in the synthesized model to begin to create causal relationships and promote analyses $(34,35)$. We then compared these themes again to those identified by the HP team and the literature to assess the fit between case study themes and the conceptual model.

\section{Results}

The results of this case study reinforced the use of the conceptual model (Figure 2) to frame the analysis of the role of political context, the power bases of different social actors, and the combination of change strategies (political actions vs. public health evidence and other technical strategies) to create system changes of sustainable health promotion policies for improved health goals. Our adapted power-analysis tool captured the perceptions of different stakeholders of their participation, and the factors that facilitated or constrained health policy change. The participatory involvement of health promotion staff throughout the study enabled us to ground the results from the power analysis instrument in practice, and confirmed the importance of CBPR approaches within health promotion inquiry.

To summarize the results, we created categories (summarized in Table 1) of facilitators, barriers, and tensions related to sustainability under each theme: power contexts; stakeholder/social actor roles (health promotion team and community members); strategies for change; and system outcomes (i.e. community capacity, sustainability, and policies). Each theme is described below.

\section{Power context}

To present the power context, we first give an overview of New Mexico's adolescent health statistics, and the federal and state policy environment surrounding these statistics. New Mexico's teen health statistics have historically been among the worst in the nation. In 2005 (the time of the start of the coalition, New Mexico for Responsible Sex Education - NMRSE), its teen birth rate was 64.3 per 1000, as compared to the US: 41 per 1000; with NM Hispanic teens at 85 per 1000 , among the highest in the nation (36). In a 2005 survey of NM high school students, $32.8 \%$ reported being sexually active, with added risk factors for pregnancy, such as $26.3 \%$ reporting alcohol or drug use, and $42.7 \%$ not using a condom the last time they had sex (37). These statistics spurred the NMDOH to adopt the prevention of teen and other unintended pregnancies as a strategic priority, which provided the mandate for health promotion staff to become key technical staff within the emerging NMRSE Coalition.

The context for US policy-making is a complex balance between state and federal authority. While states control the majority of regulatory education and health policies, federal legislation, with access to federal dollars, influences policy-makers at both state executive and legislative levels. Federal dollars, in fact, were highly relevant in this circumstance. In 2004, funding from the federal policy 'Title V: abstinence-only-until-marriage' Act provided US\$1,336,251 to the $\mathrm{NMDOH}$ for adolescent school-based instruction. While national research indicates that abstinence programs work best among adolescents not yet sexually active (38), in 2004, the NM Democratic party governor 


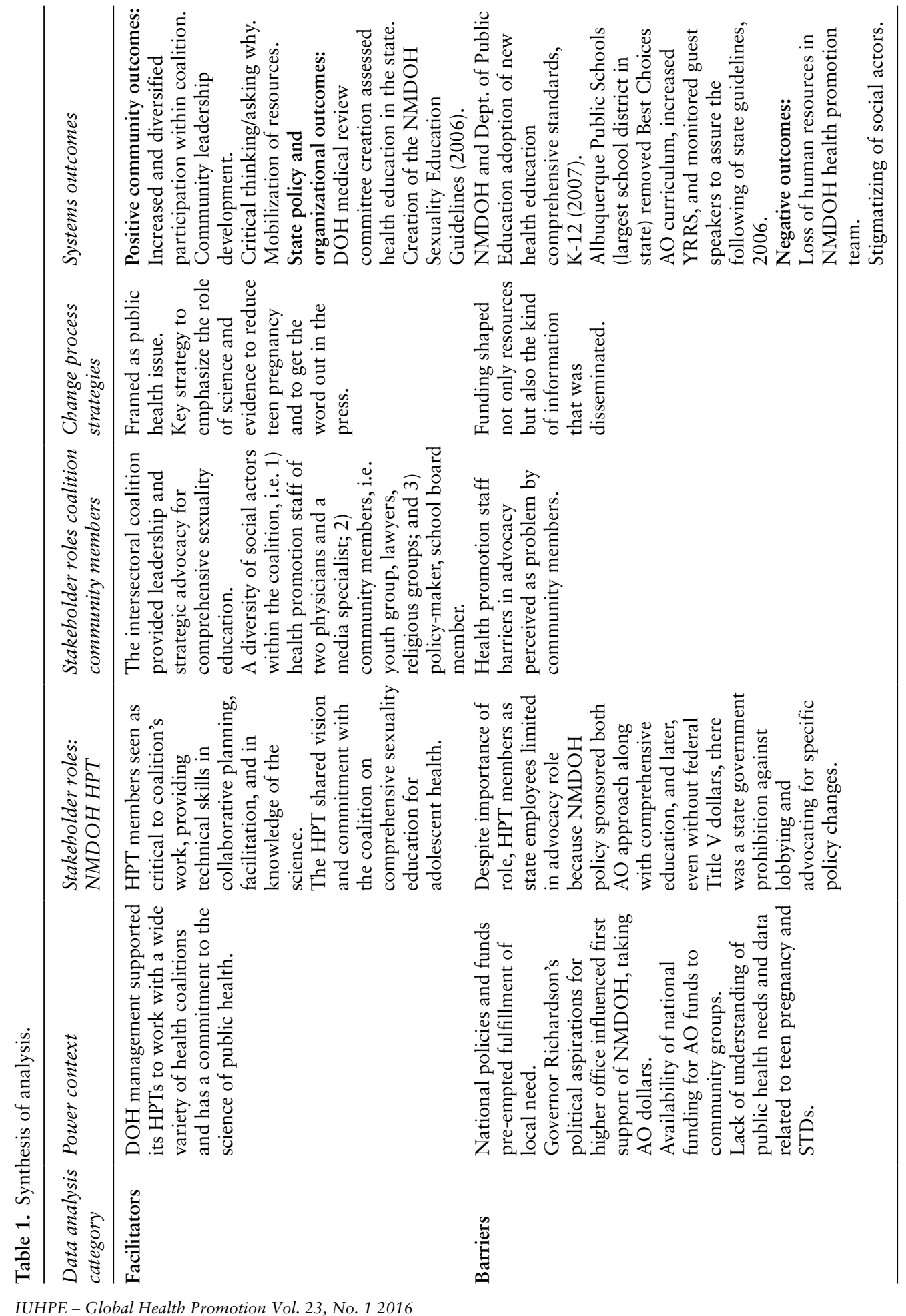




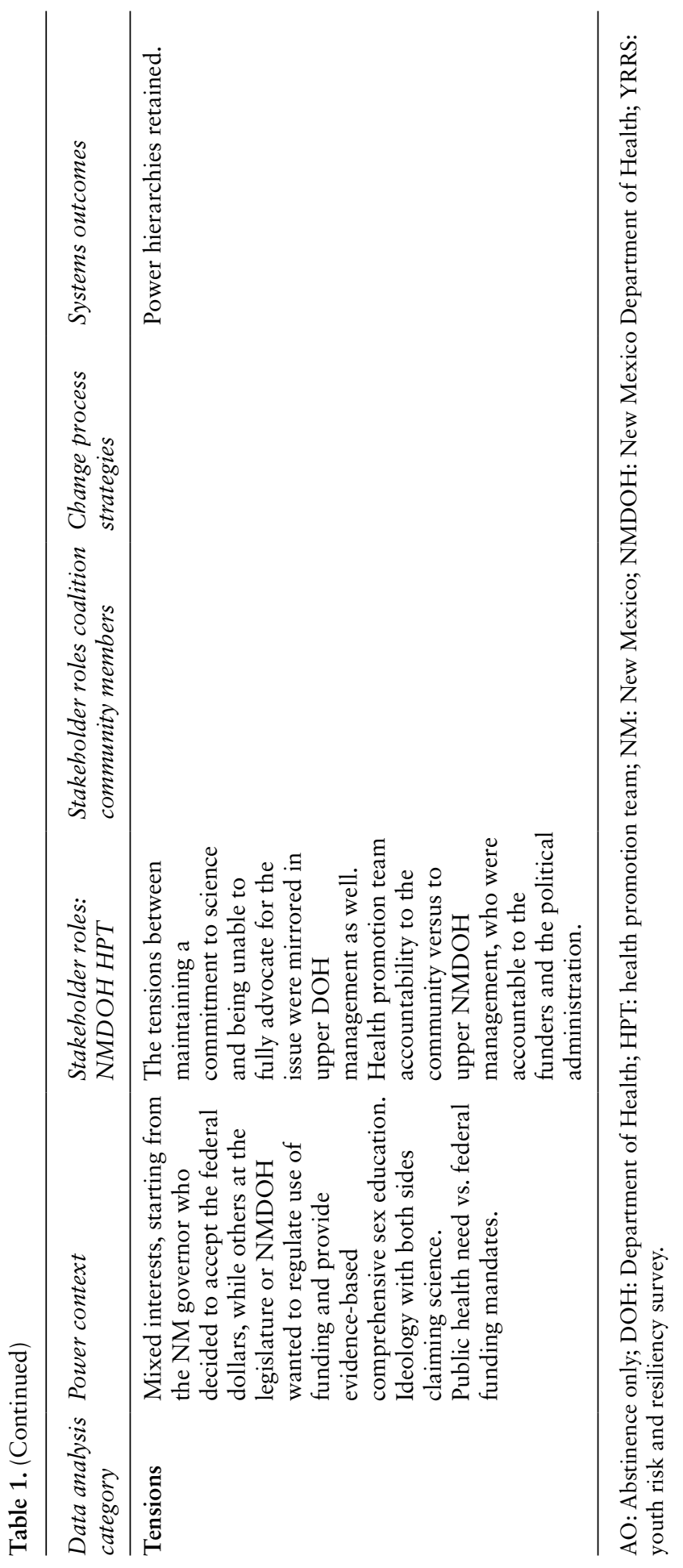


accepted the federal Title $\mathrm{V}$ abstinence-only funding for the NMDOH. Coalition advocacy and complaints about medical inaccuracies, however, in the next two years, led to the NMDOH taking the bold step of restricting funding to grades six and below in January 2006, while seeking a federal waiver for older students. The Republican federal government rejected the NMDOH's application and stopped sending the allocated funds to the state. In November 2006, the NMDOH released comprehensive sexuality education guidelines (39), and in its application for Fiscal Year 2007 federal funding, proposed using its allocation to work on college campuses and with parents, an application that was also rejected by Washington.

In January 2007, the NM Department of Public Education (NMPED) used the NMDOH guidelines to adopt comprehensive Health Education Standards for K-12 grade (40), as a continued NM state policy commitment to broad-based sexuality health education, rather than following restrictive federal policy. Despite the NMDOH comprehensive policy preventing receipt of Title V money (41), abstinenceonly federal funding still came directly to community groups (US\$1,336,466 in 2007) (42). In addition, each school district had the autonomy to select the health education content that was offered. With this large influx in funds, the NMRSE Coalition by 2008 had to redirect its advocacy to prevention messages to supplement the community-provided abstinence-only programs, and to advocate for more comprehensive education on a school-district-by-district basis.

Our interviews provided insights into the struggle between national abstinence-only funding and state policy-making, in the face of high unintended pregnancy rates and in light of the interest of many state health promotion staff and their $\mathrm{NMDOH}$ managers to have a comprehensive educational approach. A quote from a coalition community member illustrates the power of the funding source:

Who has control over the money is really the Feds because they are not letting the state do what it needs to. They have final say. Nationally the government has hindered our progress by not supporting decisions based on needs of NM... The federal government sent dollars directly to [faith-based] contractors. The largest abstinenceonly grantee in NM [Best Choices] had control of money and they abused their power over those resources. They also had access to policy-makers with control at national level.

Although the national context was challenging, the $\mathrm{NMDOH}$ management assisted its regional health promotion teams in important ways: by supporting them to staff a wide variety of health coalitions, including the NMRSE Coalition; and by seeking guidance from the scientific community on evidencebased strategies. Though often public health science is challenging in that it may be contradictory, the evidence-base for teen pregnancy prevention has been evolving since the 1990s. In reviews by the Centers for Disease Control and others (43-45); in individual research studies $(46,47)$; and more definitively, in two more recent systematic reviews by the US Community Preventive Services Task Force (48); comprehensive sexuality education has been identified as more effective than abstinence-only interventions.

Despite the growing evidence, politics had a role in state decision-making. Coalition members perceived the Democratic governor didn't want to fully reject federal dollars and thus jeopardize his political capital with state Republicans, since he was considering a run for the 2008 US presidency. Others in state legislature or the $\mathrm{NMDOH}$ wanted to provide comprehensive sex education and as a minimum hoped they could regulate the funding. A coalition community partner stated:

State policies were vague previous to the formation of the coalition [in 2005] and have since become more supportive of preventive teen pregnancy measures. Social and political roles have been huge in creating a climate where for each step forward we have to take two steps back. Positively, the state has done extensive research to establish needs and disparities... We know that although a lot of state policy-makers have supported and backed our issue in words, they haven't done so in actions, because it's a controversial issue.

Ideology played a role in that both sides claimed that their positions were based on science. A top NMDOH manager said:

A key learning has been that when people talk about science, we don't know whose science we're talking about. It's been a problem because both sides point to science. On the other hand, their 
misinformation [was] medically wrong, medically incorrect, and a lot based on shame and fear and Christian politics and principles.

\section{Another NMDOH senior director stated:}

The coalition, in my recollection, tried to get the most accurate information out to decision makers, but the abstinence-only folks were also coming with information, but this was not objective data. It's amazing how they manipulated information.

Within the overall political context, stakeholder capacities and authority to engage in a range of actions became an important explanatory context for understanding which change strategies were used by different actors. The following two sections present respondent understandings of the roles and actions of health promotion team members and community members of the coalition.

\section{Stakeholder/social actor roles: health promotion team}

Many key informants declared HP team members critical to coalition advocacy through their technical planning and facilitation skills; their knowledge of the evidence; and their commitment to work on adolescent health through the NMRSE Coalition. Community members stated:

The role of the health promotion team has been as catalyst, support and [they were] very active, but they were great at handing off leadership... I think they've been the biggest resource we've had... The basic organization and maintenance of the coalition and the reaching out to other participants was a credit to the health promotion team, not necessarily being out front, but the ones that kept it together, to strategically plan the next steps, organizationally and politically.

Despite the importance of their role, as state employees, health promotion staff faced restrictions on their advocacy; state policies prohibited state employees from lobbying and speaking to the media. As stated by community members:

Without the HP team, this coalition would not exist... Right now we're working with our legal advisors to keep them involved without putting them at risk... My fear is key people will feel pushed out... It is sad.

The DOH staff, they play an important role; they have the experience that community folks do not have. But community folks can do what $\mathrm{DOH}$ staff cannot do, like lobbying.

Health promotion is often silent because it has to be behind the scenes because it's so political.

A health promotion staff member echoed this tension:

Indirect [pressures]; nobody ordered me not to participate, but all DOH employees' emails were monitored because of legal actions and public requests from abstinence-only [groups], and we are not allowed to testify publicly ... Our hands are continually being tied.

The tensions between maintaining a commitment to science and being unable to fully advocate for the issue were mirrored in upper $\mathrm{NMDOH}$ management as well. A middle level HP manager within $\mathrm{NMDOH}$ stated:

I think it was our organization that identified that this was an issue and having one of our health promotion staff sit on the review board was critical. Our organization influenced all of the other organizations. That was both positive and negative. At times, I had to keep quiet and suck it up. I supported our staff to work openly and honestly with the community. At the district level, we have some knowledgeable and passionate staff. They inspire and influence me.

\section{Stakeholder/social actor roles: community members in the coalition}

Many key informants indicated the coalition's importance in providing leadership and strategic efforts to develop new state guidelines and regulations, as summarized by a community coalition member:

It is a remarkable success; we were so effective; we planned, we grew ... We work through difficult IUHPE - Global Health Promotion Vol. 23, No. 12016 
times and maintain the respect for each other ... I have not seen this [in] any other efforts ... We got the issue at a critical time. The fact that we have formalized the coalition, we have more people involved, we are in a great position.

The diversity of social actors within the coalition was mentioned, with specific reference to HP team members, two physicians; the youth group, Young Women United; and a school board member. This was indicated by a senior NMDOH staff member: 'The diversity of thegroupwasonethatallowed forgood communication; we have staff experienced in media and working with policy-makers'. A community member reinforced the strength of diversity: 'Influence has been that between us all, we've brought every voice that needs to be there: youth, medical, parents; and working with the state $[\mathrm{DOH}]$ has been surprisingly great'.

\section{Change strategies (public health science versus advocacy)}

This section reviews respondents' perceptions of the power of different strategies in promoting system outcomes of sustainability and policy change. A key strategy expressed repeatedly was the role of science and using evidence-based teen pregnancy statistics. One of the NMDOH managers said explicitly, 'There's greater proof, greater evidence, over a long period of time that supports the comprehensive approach. Informed decision-making is the foundation of public health'. A community coalition member also provided support for evidence in the media. 'People see this issue in the press; help[s] us get evidence to policy-makers. The strategic messages have created sustainability'.

Framing the issue as a public health matter was also named as important. A community-based provider coalition member stated,

The issue is a basic question of how we as [a] society prepare young people for healthy life. The way I define it as a public health issue is to give young people comprehensive health education, information and support.

An elected official also talked about public health as a:

general public health issue. Not to give young people comprehensive sex education, health information and support is misinformation, medically wrong, medically incorrect ... creat[ing] shame and fear [from] right Christian politics principles ... Most young people affected are minorities' families; the Spanish speaking, immigrant population will be affected disproportionally.

Barriers and tensions remained about how funding could shape not only the available resources but also the kind of information that was disseminated. As said by a senior NMDOH manager:

The Bush Administration, the power of millions of dollars without evidence-base, has the control. The coalition was great in getting information out, and [it] continues to coordinate well with the resources that they have, but the power of the Administration is enormous ... Another barrier can be the black hole of politics and elected/ appointed officials ... The big barrier is a governor that will not go against Bush. There are a lot of people to support this initiative. The coalition was successful ... [in moving] the issue in different levels of state organizations.

\section{System outcomes}

As a result of the distinct change strategies of science and advocacy and the interaction between community and governmental actors, there were important organizational practice and health policy outcomes at the state level. These included the Secretary of Health's 2007 rejection of abstinence-only funds and new standards, after several years of coalition activity $(40,41)$. Despite federal funding and ambivalence within state policy-makers at the governor's level, an NMDOH senior official highlighted the possibility of policy development across state agencies:

Having a comprehensive sex education policy for $\mathrm{NMDOH} \ldots$ participating in developing the [Public Education Department Health Education] standards ... NMDOH had a key role and helped make this a sustainable initiative. The coalition helped bring about a sustainable initiative.

Community capacity and leadership development among coalition members were touted as important outcomes. One director of a community-based organization mentioned: 
...networking and collaboration ... The whole idea of coordinating services, knowing who's doing what and where. Benefits have also been the overwhelming support for the health and wellbeing of young women of color ... Its [the coalition's] ability to communicate is good. Members have solid information, good facts.

The supportive Secretary of Health moved into a successful political career, and is currently a national Congresswoman. Several NMDOH staff also retired and remain strong community advocates for adolescent health. On the negative side, there were changes in health promotion staffing, with many who had supported the coalition leaving the NMDOH. Two HP staff favorable to abstinenceonly approaches were promoted and are still working in $\mathrm{NMDOH}$.

\section{Discussion}

This study sought answers to questions which have challenged health professionals, policy-makers, and researchers interested in sustaining health promotion coalitions and interventions aimed at policy changes in controversial political environments. We sought to explore the research questions of whether and how community-level health promotion multi-sectoral networks and coalitions can create opportunities for sustainability through collective actions, and how distinct strategy roles within coalitions (for community members or public sector health promotion professionals) can facilitate health policy change even in adverse political and power contexts.

Our case study demonstrated results for five categories in our conceptual model related to questions of social networks and health promotion sustainability: the importance of the power context (in this case federal vs. state policy); health promotion team roles; community member roles; change strategies; and outcomes. While this case study had as its context a contentious health promotion issue, key informants identified spaces for effective health promotion actions and strategies with a network of diverse actors, including withinstate government. While illustrating that health promotion cannot just be seen as a value-free endeavor, the case study also demonstrated the strategies that health promotion professionals used to enter the political realm. State health promotion employees within the NMDOH were able to provide technical assistance and evidence-based data to the coalition, and to engage in internal advocacy within their own bureaucratic power structure and to their boss, the Secretary of Health. The framing of sexuality education, in particular as a public health and health promotion issue based on evidence, enabled broader dialogue and the potential for the $\mathrm{NMDOH}$ to be involved in health promotion public policy development. With the diversity of social actors with different sources of power within the coalition, the health promotion team was able to rely on their community partners to take the lead in public discourse, advocacy, and lobbying.

The potential limitations to this study include: conducting CBPR research with a single health promotion team to incorporate their practicebased experience; retrospective interviews with stakeholders; ethical challenges in protecting confidentiality; and having few key informants who were opponents to comprehensive sex education. Though a single health promotion team, the CBPR process effectively demonstrated a complementarity between soliciting practitioner input and the literature for constructing the definitions and the model; a broader group of respondents added validity to the constructs chosen in the model. Recall bias was also minimized for coalition members and $\mathrm{NMDOH}$ respondents because most were still actively involved in the issue during the interviews.

We did face ethical challenges in both collecting and reporting the data in terms of maintaining confidentiality within a small state where people are known. Although key informants were possibly cautious in their responses, there was triangulation of key themes, such as advocacy vs. evidence-based technical roles, understanding of state policy challenges within federal funding, or health promotion team vs. community member actions. We were careful, in addition, to hide direct identifiers in the reporting of quotes. Finally, the study was indeed limited in its understanding of the perspective of abstinence-only supporters, though focus was maintained on the primary inquiry: to deepen understanding of how diverse health promotion and community actors can be successful in creating sustainable health promotion initiatives and policies. The importance of the power context; roles within social networks or organizations; and the effectiveness 
of advocacy (including media) vs. science-based public health framing strategies was reiterated.

Framing policy issues so they can move into the public discourse has been identified as key for policy development that includes stages of problem identification, strategic policy choice, policy advocacy, and implementation (49-51). While these stages are not linear, nor inevitable, this case study adds to the literature by illuminating the types of sustained collective and political action needed, as well as the strategic roles of the diverse players within the inter-sectoral networks to work with policy-makers (or to pressure them) to create health promotion policy changes.

Increasingly, practitioners of health promotion policy recognize the importance of struggling 'for discursive hegemony in which actors try to secure support for their definition of reality' (52). By weaving a selection of facts and values into a plausible prescriptive narrative, policy frames or storylines allow actors to reduce the complexity of policy problems, ascribe meaning to problems, and assess possible policy alternatives within difficult or contentious power politics.

Our assumption was validated that an intersectoral health promotion coalition with distinct roles for community and professional stakeholders could create sustainable actions for health policy outcomes. We also affirmed that coalitions would be more effective if there was flexibility to maneuver between confrontational advocacy and collaborative educational evidence-based strategies, and to build community leadership as a capacity outcome, in addition to policy change. Our findings reinforced the idea that understanding power dynamics is critical to explaining how research evidence is used, and that the construction of 'evidence' is a required discursive strategy for policy-making (52-55). While political science may have much to teach public health and health promotion in its understanding of the power of deliberation, discourse, and citizen engagement, political scientists may also have much to learn from health promotion professionals, who are increasingly more seasoned in their intersectorial collaboration and the complexity of the health policy-making process (56-58).

\section{Conclusion}

This study aimed to examine the sustainability and power relations within a single health promotion initiative of a comprehensive sexual health education coalition in our search for wider and longer-lasting solutions for these initiatives. To better understand the complex systems of social actors and institutions, our 'power-analysis' instrument focused on analyzing stakeholders' perceptions of their roles, their power to formulate political agendas, and their ability to build social networks and other intersectoral collaborations that can strengthen health promotion initiatives, increase community participation, and contribute to healthy policies. While this in-depth study of stakeholder views and positions of power might be difficult to replicate in typical evaluation settings, the dimensions of the model may be useful for practitioners concerned with the sustainability of health promotion initiatives. The model suggests the importance of: 1) assessing the power context, i.e. the policy environment and the power bases of stakeholders within their social networks; 2) identifying change strategies that include both advocacy and the use of public health science to reach constituents, including policy-makers; and 3) evaluating a range of system change outcomes, including capacity-building and sustainability. This model, while coming from a particular process, complements another CBPR policy model in its dimensions of context, partnering dynamics, policy stages and outcomes, including sustainability (59).

By elucidating sustainability as a theoretical and practical construct, we hope our findings will facilitate health promotion professionals and policymakers to further use our model and to recognize the importance of analyzing power and roles in social networks within the wider context of international health promotion initiatives, in order to seek sustained impact on politics and on equity for all health policies.

\section{Funding}

This research received no specific grant from any funding agency in the public, commercial, or not-for-profit sectors.

\section{Acknowledgements}

We appreciate the contribution from the New Mexico Department of Health, Region 1's Health Promotion 2003- 2007 team in sharing their perspectives and ideas in the research, in particular, Michelle Melendez, Francisco Ronquillo, Miguel Acosta, Enrique Cardiel, Jerry Montoya and Lorenzo Garcia. 


\section{References}

1. Minkler M, Wallerstein N. Community-Based Participatory Research for Health: From Process to Outcomes. 2nd Ed. San Francisco, CA: Jossey-Bass; 2008.

2. Chalmers ML, Housemann RA, Wiggs I, NewcombHagood L, Malone B, Brownson RC. Process evaluation of a monitoring log system for community coalition activities: five-year results and lessons learned. Am J Health Promot. 2003; 17: 190-196.

3. Pluye P, Potvin L, Denis JL, Pelletier J. Program sustainability: focus on organizational routines. Health Promot Int. 2004; 19: 489-500.

4. Pluye P, Potvin L, Pelletier J. Community coalitions and health promotion: is it that important to develop an inter-organisational network? Promot Educ. 2004; 11: 17-23.

5. Scheirer MA, Hartling G, Hagerman D. Defining sustainability outcomes of health programs: illustrations from an on-line survey. Eval Program Plann. 2005; 31: 335-346.

6. Tang KC, Nutbeam D, Kong L, Wang R, Yan J. Building capacity for health promotion-a case study from China. Health Promot Int. 2005; 20: 285-295.

7. Nguyen MN, Gauvin L, Martineau I, Grignon R. Sustainability of the impact of a public health intervention: lessons learned from the Laval walking clubs experience. Health Promot Pract. 2005; 6: 44-52.

8. Swerissen H, Crisp BR. The sustainability of health promotion interventions for different levels of social organization. Health Promot Int. 2004; 19: 123-130.

9. Perreira Lima VL, Arruda JM, Barroso MA, Lobato Taveres MF, Ribeiro Campos NZ, Zandonadi RC, et al. Analyzing the outcomes of health promotion practices. Promot Educ. 2007; 14: 21-26.

10. Freitas CM, Porto MF, Moreira JC, Pivetta F, Machado JM, Freitas NB, et al. Chemical safety, health, and environment: prospects for governance in the Brazilian context. Cad Saude Publica. 2002; 18: 249-256.

11. Baldwin L, Abernethy P, Roberts L, Egan H. Forming, managing and sustaining alliances for health promotion. Health Promot J Aust. 2005; 16: 138143.

12. Greenberg MT. Current and future challenges in school-based prevention: the researcher perspective. Prev Sci. 2004; 5: 5-13.

13. Brown VA, Ritchie J. Sustainable communities: what should our priorities be? Health Promot J Aust. 2006; 17: 211-216.

14. Burke NM, Chomitz VR, Rioles NA, Winslow SP, Brukilacchio LB, Baker JC. The path to active living: physical activity through community design in Somerville, Massachusetts. Am J Prev Med. 2009; 37: S386-394.

15. Draper AK, Hewitt G, Rifkin S. Chasing the dragon: developing indicators for the assessment of community participation in health programmes. Soc Sci Med. 2010; 71: 1102-1109.
16. Franca LM, Mantovaneli Junior O, Sampaio CAC. Governança para a territorialidade e sustentabilidade: a construção do senso de regionalidade. Saude soc. 2012; 21: 111-127.

17. World Health Organization. Adelaide statement on health in all policies moving towards a shared governance for health and well-being 2010. Available from: http://www.who.int/social_determinants/hiap_ statement_who_sa_final.pdf (accessed 11 September 2014).

18. Nchinda TC. Research capacity development for CVD prevention: the role of partnerships. Ethn Dis. 2003; 13: S40-44.

19. Reinfurt DW. Documenting the sustainability of a mature Click It or Ticket program: the North Carolina experience. J Saf Res. 2004; 35: 181-188.

20. Ehlers J, Palermo T. Community partners for healthy farming intervention research. J Agr Saf Health. 2005; 11: 193-203.

21. Nordqvist C, Timpka T, Lindqvist K. What promotes sustainability in Safe Community programmes? BMC Health Serv Res. 2009; 9: 4.

22. Vermeer AJM, van Assema P, Hesdahl B, Harting J, de Vries NK. Factors influencing perceived sustainability of Dutch community health programs. Health Promot Int. 2013; 9: 1-11.

23. Cardno EJ. Managing the 'fit' of information and communication technology in community health: a framework for decision making. J Telemed Telecare. 2000; 6: S6-8.

24. Svanstrom L, Welander G, Ekman R, Schelp L. Development of a Swedish bicycle helmet promotion programme-one decade of experiences. Health Promot Int. 2002; 17: 161-169.

25. Moysés SJ, Moysés ST, Krempel MC. Avaliando o processo de construção de políticas públicas de promoção de saúde: a experiência de Curitiba. Ciênc Saúde Coletiva. 2004; 9: 627-641.

26. Sule SS. Community participation in health and development. Niger J Med. 2004; 13: 276-281.

27. Dressendorfer RH, Raine K, Dyck RJ, Plotnikoff RC, Collins-Nakai RL, McLaughlin WK, et al. A conceptual model of community capacity development for health promotion in the Alberta Heart Health Project. Health Promot Pract. 2005; 6: 31-36.

28. Harris N, Sandor M. Defining sustainable practice in community-based health promotion: a Delphi study of practitioner perspectives. Health Promot J Aust. 2013; 24: 53-60.

29. Gallo E, Setti AFF. Abordagens ecossistêmica e comunicativa na implantação de agendas territorializadas de desenvolvimento sustentável e promoção da saúde. Ciênc saúde coletiva. 2012; 17 : 1433-1446.

30. Buss PM, Gallo E, Magalhães DP, Setti AFF, Netto FAF, Buss DF. Governança em saúde e ambiente para o desenvolvimento sustentável. Ciênc saúde coletiva. 2012; 16: 1479-1491.

31. Santos BS. A critica da razao indolente-contra a desperdicio da experiencia. 2da. ed. Sao Paulo: Cortez Editora; 2000. 
32. Mayers J. Stakeholders power analysis London, UK. International Institute for Enviromental Development 2005. Available from: http://www.policy-powertools. org.

33. Glaser BG, Strauss AL. The discovery of grounded theory: strategies for qualitative research. Chicago: Aldine Pub. Co.; 1967.

34. Creswell JW. Research Design: Choosing Among Five Approaches. Thousand Oaks, CA: Sage Publishers; 2013.

35. Stake RE. The Art of Case Study Research. Thousand Oaks, CA: Sage Publishers; 1995.

36. Mathews TJ, Sutton PD, Hamilton BE, Ventura SJ. State disparities in teenage birth rates in the United States. NCHS Data Brief. 2010; 46: 1-8.

37. NMDOH. New Mexico Youth Risk and Resiliency Survey YRRS 2006. Available from: http://www.health. state.nm.us/pdf/2005YRRSstatewideReport.pdf.

38. Santelli J, Ott MA, Lyon M, Rogers J, Summers D, Schleifer R. Abstinence and abstinence-only education: a review of U.S. policies and programs. J Adolesc Health. 2006; 38: 72-81.

39. NMDOH. New Mexico Department of Health Sexuality Education Guidelines 2006. Available from: http://www.health.state.nm.us/pdf/Sexuality EducationGuidelines.pdf.

40. NMPED. New Mexico Public Education Department. Health Education Standards with Benchmarks and Performance Standards, 2007. Available from: http:// www.ped.state.nm.us/SchoolFamilySupport/dl08/ $\mathrm{HE} \% 20$ Standards.pdf.

41. Sexuality Information and Education Council of the United States (SIECUS). New Mexico Rejects Title V Federal Abstinence-Only-Until-Marriage Funds, 2007. Available from: http://www.siecus.org/index. cfm? fuseaction=Feature . showFeature $\&$ featureid $=905$ \&pageid=483\& parentid=478 (accessed July 10, 2014).

42. SIECUS. New Mexico State Profile. 2008. http:// www.siecus.org/_data/global/images/State \% 20 Profiles \%20FY\%2008/NEW\%20MEXICO.pdf (accessed 11 September 2014).

43. Kirby D. (2007). Emerging Answers 2007: New Research Findings on Programs to Reduce Teen Pregnancy -Full Report. Washington, DC: The National Campaign to Prevent Teen and Unplanned Pregnancy. http://thenationalcampaign.org/resource/ emerging-answers-2007-full-report (accessed 11 September 2014).

44. Kirby D. Emerging Answers 2007: Research Findings on Programs to Reduce Teen Pregnancy and Sexually Transmitted Diseases. Washington, DC: National Campaign to Prevent Teen Pregnancy; 2007.

45. CDC analysis finds comprehensive sex ed is more effective than abstinence only. Contemporary Sexuality. 2010; 44(1): 8 .
46. Kirby D. The impact of abstinence and comprehensive sex and STD/HIV education programs on adolescent sexual behavior. Sex Res Soc Pol. 2008; 5: 18-27.

47. Kohler PK, Manhart LE, Lafferty WE. Abstinenceonly and comprehensive sex education and the initiation of sexual activity and teen pregnancy. J Adolesc Health. 2008; 42: 344-351.

48. Chin HB, Sipe TA, Elder R, Shawna L, Mercer SL, Chattopadhyay SK, et al. The effectiveness of groupbased comprehensive risk-reduction and abstinence education interventions to prevent or reduce the risk of adolescent pregnancy, human immunodeficiency virus, and sexually transmitted infections: two systematic reviews for the Guide to Community Preventive Services. Am J Prev Med. 2012; 42: 272-294.

49. Longest BB Jr. Health Policymaking in the United States. 4th Ed. Chicago: AUPH/Health Administration Press; 2006.

50. Kingdon JW. Agendas, Alternatives, and Public Policies. 2nd edition, New York: Longman; 2010.

51. Themba-Nixon M, Minkler M, Freudenberg N. The Roles of CBPR in Policy-Advocacy, CBPR for Health: From Process to Outcomes. 2nd Ed., edited by Minkler M, Wallerstein N. San Francisco: JosseyBass; 2008, 307-320.

52. Hajer MA. The Politics of Environmental Discourse: Ecological Modernization and the Policy Process. Oxford: Oxford University Press; 1997.

53. Fafard P. Public health understandings of policy and power: Lessons from INSITE. J Urban Health. 2012; Dec; 89(6): 905-914.

54. Murphy K, Fafard P. Knowledge Translation and Social Epidemiology: Taking Power, Politics and Values Seriously, Rethinking Social Epidemiology: Towards a Science of Change, P. O'Campo and J.R. Dunn (eds.), New York, Springer, 2011, 267-283.

55. Kickbusch I, Buckett K. Implementing Health in all Policies: Adelaide 2010. Adelaide: Government of South Australia; 2010.

56. Breton E, De Leeuw E. Theories of the policy process in health promotion research: a review. Health Promot Int. 2011; 26: 82-90.

57. Hofrichter R. Health and Social Justice: Politics, Ideology, and Inequity in the Distribution of Disease. San Francisco: Jossey-Bass; 2003.

58. Serrate PC-F. Intersectorialidad en Salud: Fundamentos \& Aplicaciones. La Habana, Cuba: Editorial Ciencias Medicas; 2010.

59. Cacari-Stone L, Wallerstein N, Garcia A, Minkler M. The promise of community-based participatory research for health equity: a conceptual model for bridging evidence with policy. Am J Publ Health. 2014; 104: 1615-1623. 